\title{
THE IMPORTANCE OF MEASURING INEQUITIES IN INCOME DISTRIBUTION RATHER THAN INEQUALITIES: PUBLIC POLICY IMPLICATIONS
}

\author{
William L. Casey, Jr., Babson College, Babson Park, MA, U.S.A.
}

dx.doi.org/10.18374/RBR-19-2.9

\begin{abstract}
Issues relating to the perceived inequalities in income distribution are at the center of the political debates taking place currently in the U.S. and elsewhere. Unfortunately, the issues are clouded by the failure to distinguish between inequality in income distribution, which may be justified, and inequity in income distribution, which never is. Furthermore, the traditional method used by economists to measure inequality, the Gini Coefficient, is flawed and particularly unreliable in measuring different conditions of inequality in different countries. A popular policy initiative, recommended by some as a way to redistribute income more equitably, is the â€ universal basic income' approach. However, there are serious questions about whether this approach is progressive or regressive. A promising alternative may be a variation of the "Environmental Context Dashboard" approach adopted by the College Board in addressing the need to give disadvantaged students better access to the best U.S. colleges and universities.
\end{abstract}

Keywords: Inequality in Income Distribution, Inequity in Income Distribution, Gini Coefficient, Universal Basic Income, Environmental Context Dashboard, Landscape Approach. 